\title{
Narrativas visuais e propaganda cristã: uma análise dos artefatos em vidro dourado na Antiguidade Tardia
}

\author{
Visual narratives and Christian propaganda: an analysis of the \\ golden glass artifacts in Late Antiquity
}

Ludimila Caliman Campos*

\begin{abstract}
Resumo: O presente artigo teve por objetivo analisar o programa propagandístico comemorativo empreendido pelos cristãos na Antiguidade Tardia. Para tanto, fizemos leituras iconográficas e epigráficas de algumas peças decorativas em vidro dourado, com destaque para as que fazem referência a Pedro e Paulo. Por meio de uma interpretação das formas de visibilidade presentes nesses artefatos, buscamos compreender as alterações político-religiosas que caracterizaram a ekklesia cristã nos séculos IV e V, com destaque para a apoteose do poder episcopal e a institucionalização eclesiástica.
\end{abstract}

\begin{abstract}
This article aimed to analyse the commemorative propaganda program undertaken by Christians in Late Antiquity. For that, speeches iconographic and epigraphic readings of some decorative pieces in golden glass, with emphasis on those that refer to Pedro and Paulo. Through an interpretation of the forms of visibility the artifacts present, we seek to understand the political-religious changes that characterized Christian ekklesia in the 4th and 5th centuries, with emphasis on the apotheosis of episcopal power and ecclesiastical institutionalization.
\end{abstract}

Palavras-chave:

Propaganda.

Vidro Dourado.

Cristianismo.

Antiguidade Tardia.

\author{
Keywords: \\ Propaganda. \\ Golden Glass. \\ Christianity. \\ Late Antiquity.
}

\footnotetext{
* Professora titular e pesquisadora da Faculdade de Ensino Superior de Linhares (Faceli). Colaboradora nacional do Laboratório de Estudos sobre o Império Romano (Leir/ES) e coordenadora do Laboratório Cultura, Representação e Imagem em Estudo (Crie/Faceli).
} 


\section{Introdução}

propaganda é um fenômeno histórico. Para os desavisados, a propaganda
teria surgido com a invenção da prensa móvel por Gutenberg, no século XV, e
ganhado força com as várias inovações promovidas pela indústria da tecnologia da informação, com destaque para o rádio, a televisão e a internet. Todavia, se olharmos mais detidamente para o passado, perceberemos que a propaganda surge, na verdade, com o nascimento das primeiras cidades, quando a difusão de informações se tornou absolutamente necessária para as relações políticas, econômicas, sociais e religiosas. Evan Sage (1916, p. 204) pontua que, entre os romanos, Marcial, além de poeta e epigramatista, era um homem de negócios que teria mencionado o nome de médicos, barbeiros, perfumistas e cocheiros em suas obras exatamente porque tais profissionais pagavam por seus anúncios. A propaganda feita pelo escritor incluía informações relevantes sobre os negócios desses profissionais, como a localização de suas lojas e os preços que cobravam. No que concerne à propaganda nas paredes, o sítio arqueológico de Pompeia nos ajuda a estabelecer uma análise ainda mais aprofundada, considerando que lá foram decobertas mais de 6 mil paredes desenhadas, várias delas apresentando um caráter propagandístico, indo desde anúncios de objetos perdidos e roubados a jogos de gladiadores, eleições, protestos políticos, alugueis e perfomances teatrais. Pintados com letras grandes vermelhas ou pretas para que pudessem ser facilmente lidos, os anúncios eram mais comumente alocados nas paredes das basílicas, das casas de banho, dos teatros e dos anfiteatros, locais de maior circulação de público (SAGE, 1916, p. 206). O aumento da alfabetização da população, a expansão do Império e do comércio, bem com o desenvolvimento do sistema político romano desencadearam mudanças significativas nas pequenas comunidades agrícolas que se convertarem em cidades, o que representou uma maior competição e diversificação nas relações políticas, econômicas, sociais e religiosas no mundo da época. Nesse contexto, a propaganda se tornou parte integrante da vida cotidiana romana.

\section{Formas de visibilidade, propaganda e imagem}

A propaganda pode ser entendida como um esforço educacional ou uma informação utilizada por um grupo organizado que é disponibilizada a um público selecionado com o propósito específico de fazer com que a audiência adote determinada ação ou se conforme a determinada atitude desejada pelo grupo organizado. Além disso, a propaganda busca estabilizar opiniões e atitudes com vistas a fazer com que o indivíduo participe de uma 
sociedade em todos os sentidos (EVANS, 1992, p. 1-2). A propaganda é, desse modo, "um esforço consciente e sistemático destinado a influenciar as opiniões e ações de um certo público ou de uma sociedade total" (BOBBIO; MATEUCCI; PASQUINO, 1983, p. 1018).

A propaganda se vale de todos os instrumentos que as condições tecnológicas de seu tempo disponibilizam para cumprir seu fim, que é a difusão de ideias e a persuasão sistemática. O fenômeno, conforme assinalam Bobbio, Mateucci e Pasquino (1983, p. 1019), segue cinco princípios, a saber: a simplificação, a saturação, a parcialidade, a deformação e a falta de inovação. A simplificação se coloca na medida em que a mensagem deve ser resumida, breve e direta, de modo a atingir o maior número de pessoas de uma audiência. Já a saturação está vinculada à frequência com que essa mensagem é emitida, sendo que uma propaganda eficaz é aquela com veiculação constante. A parcialidade, por sua vez, se expressa porque a propaganda oferece uma mensagem emitida por um grupo, buscando induzir o conformismo de outros. A deformação seria caracterizada tanto pelo emprego de mensagens de forte impacto para conquistar a audiência quanto pela ausência de quaisquer elementos de dúvida ou oposição. Por fim, a falta de inovação remete ao fato de que a mensagem que a propaganda transmite não é nova, e sim vinculada ao contexto sócio-histórico no qual está inserida, só podendo ser decodificada à luz desse contexto.

No caso da propaganda política, por seu turno, esta extrapola o conceito de propaganda em si, por se configurar, naturalmente, como um dissenso, lançando mão do conceito de Jacques Rancière (1996). A propaganda política tem como agenda própria alertar a audiência para a ideologia daquele que comanda e a razão pela qual comanda. Ademais, esta estabelece a diferença, aguça o antagonismo, fortalece as opiniões e reorganiza o espaço do discurso.

A utilização de imagens na propaganda se encontra no que chamamos de formas de visibilidade. ${ }^{1}$ Para Rancière, interessa saber o que é visível, quem compreende, quem pode criar as imagens/enunciados, qual discurso é feito e para quem é dirigido. Considerando que a política se faz conferindo visibilidade a certos grupos, a imagem na política não pode ser vista como um espaço secundário na luta pelo poder - ao contrário, seria o lugar onde essa luta é travada. Logo, a utilização de imagens na propaganda política não tem como função única mostrar o visível, mas oferecer pistas acerca do dispositivo por meio do qual o visível é apreendido. A extensiva ostentação das imagens do líder político no suporte midiático, por exemplo, produz, por um lado, uma sensação de onipresença, deixando claro quem estabelece a ordem, o juízo e a doutrina e, por outro, potencializa

\footnotetext{
${ }^{1} \mathrm{O}$ termo visibilidade pode ser entendido tanto como aquilo que é dado a ver e a ser observado, quanto como algo que adquire um conjunto de significados simbólicos relacionados a acontecimentos particulares e, de certa forma, permite que algo seja reconhecido.
} 
a domesticação dos pensamentos daqueles que entram em contato com as imagens. Desse modo, a própria visibilidade se coloca como uma estratégia para apresentação pessoal do líder político, que se preocupa em construir uma imagem em adequação aos estereótipos de homem ideal. Isso se dá por meio da difusão de mecanismos de persuasão política, sistemas de representações que esclareceriam, àquele que lê, a razão de aquele governante estar no poder e de como os seus subjugados deveriam se portar.

\section{A propaganda eclesiástica em peças decorativas de vidro dourado}

Como mencionamos, ao longo de todo o Império Romano, a propaganda foi um recurso largamente utilizado por aqueles que desejavam publicizar um produto, um serviço, uma pessoa ou mesmo uma devoção. ${ }^{2}$ A ekklesia cristã romana, grupo social aqui analisado, fez uso da propaganda em seus múltiplos repertórios iconográficos. Todavia, para além dos mosaicos, afrescos e esculturas, um suporte iconográfico pouquíssimo discutido pela historiografia especializada e bastante controverso, no que concerne à propaganda religiosa, eram as peças em vidro dourado. Via de regra, as peças em vidro dourado estavam em conformidade com uma das três tipologias comuns, a saber: medalhões de retrato (medindo de 4 a 11 centímetros), bases de vasos ou taças (medindo de 7 a 10 centímetros de diâmetro) e bolhas laterais para parede (medindo de 2 a 6 centímetros de diâmetro) (LUTRAAN, 2009, p. 3-4).

Embora a técnica de criação de objetos em vidro dourado remonte à Grécia helenística, sua fabricação ganhou expressiva popularização durante a Antiguidade Tardia. ${ }^{3}$ Apesar de definida como "arte menor" pelos historiadores da arte, o processo de fabricação das peças em vidro dourado era complexo e exigia grande habilidade, o que nos faz acreditar que tais artefatos faziam parte do repertório de ornamentação de famílias mais abastadas. ${ }^{4}$ Quanto ao processo de fabricação, inicialmente se forjava um pequeno disco redondo e achatado em vidro, o qual era cortado de uma esfera fundida. Um pedaço

\footnotetext{
${ }^{2}$ Alguns historiadores da Antiguidade Clássica afirmam que Tito Lívio (59 a.C.-17 d.C) foi um dos primeiros propagandistas da história romana, com sua obra $A b$ urbe condita ("Desde a fundação da cidade"). Apesar de Tito Lívio não ter feito parte do círculo pessoal de Augusto, se reconhece que um dos maiores objetivos do escritor era resgatar exemplos e valores contidos no relato mítico acerca da fundação de Roma, de modo a moldar a romanidade e, assim, exaltar a figura de Augusto como um mito (SYME, 1959; WALSH, 1982).

${ }^{3} \mathrm{O}$ berço e o centro de arte em vidro dourado no período helenístico era a cidade Alexandria, que, inclusive, foi citada por Marcial, no século I. Todavia, escavações arqueológicas em uma antiga fábrica de vidro em Rodes encontraram restos de artefatos em vidro dourado, o que demonstra que, embora Alexandria tenha se destacado na fabricação desses objetos, não se tratava do único polo de produção de arte em vidro dourado. É digno de nota o fato de que os gregos helenísticos eram, geralmente, mais habilidosos, do ponto de vista técnico, do que os romanos, uma vez que empregavam a técnica em objetos maiores e com mais curvas e detalhes (HOWELLS, 2010, p. 248-249; BARAG, 2005, p. 184).

${ }^{4}$ Os artefatos em vidro dourado eram encomendados para consumo privado, usados pelos seus proprietários em jantares e/ou como objetos de decoração para suas habitações. Todavia, com a morte do proprietário, acontecia que, muitas
} 
de folha de ouro era então colado com goma arábica no disco. O desenho era criado a partir da raspagem das folhas de ouro coladas no disco de vidro. O recipiente principal, por sua vez, era forjado por sopro e corte. Este era, então, aquecido mais de uma vez e cuidadosamente prensado sobre o disco com o desenho, sobrepondo o fundo plano com o disco decorado de modo que eles se fundissem. O recipiente completo era, então, aquecido uma última vez para completar a fusão. Embora os relatos sobre a fabricação desses objetos variem um pouco quanto à sequência precisa dos estágios, o processo é essencialmente o mesmo (GRIG, 2004, p. 204).

A maior parte desses objetos chegou até nós a partir das descobertas feitas nas catacumbas romanas após algumas explorações mais formais datadas do século XVI (WHITEHOUSE, 1996, p. 5). Considerando que, nas catacumbas, os corpos eram depositados em pequenos loculi, muitas vezes empilhados uns sobre os outros em longos e estreitos corredores, as peças em vidro dourado, alocadas junto às sepulturas de seus proprietários e fixadas com o auxílio de argamassa se tornavam uma espécie de selo da sepultura, ${ }^{5}$ servindo, portanto, de lápides. ${ }^{6}$

Atualmente, há cerca de 500 artefatos em vidro dourado, entre peças inteiras e discos fragmentados. ${ }^{7}$ Datados dos séculos III ao $\mathrm{V}$, os artefatos apresentam imagens que incorporam uma ampla variedade de assuntos seculares e religiosos, a maioria dos quais frequente na arte romana tardia. ${ }^{8}$ Sobre as temáticas mais comuns, dividiremos por grupos religiosos, a saber: nas peças cristãs, encontramos figuras religiosas (santos, autoridades eclesiásticas e símbolos sagrados), bem como retratos familiares, com destaque para os casais; nos medalhões judeus, encontramos simbologias religiosas como a menorá e a arca da aliança; e nos medalhões pagãos, encontramos retratos de famílias, também com destaque para os casais, bem como figuras da mitologia greco-romana e representações políticas. No que concerne às inscrições, é possível identificar que a maior parte delas acompanha alguma imagem e inclui títulos denominativos, nomes, vocativos e/ou alguma forma de bênção, exortação ou aclamação.

vezes, o detalhe decorado em ouro era cortado e aparado para deixar apenas a parte ornada em ouro. Presumivelmente, em outros casos, os vasilhames já haviam se quebrado por conta do seu curso normal de uso.

${ }^{5}$ Os artefatos eram alocados na parede do loculus com argamassa ou estuque. Vale destacar que, para esconder os pedaços quebrados e mal forjados dos medalhões, e considerando que eram parte de uma outra peça, vários deles ainda preservam pedaços de argamassa ao seu redor, os quais sobrepõem as bordas ásperas dos vidros exatamente para esconder as partes pouco talhadas.

${ }^{6}$ Além do vidro dourado, outros objetos destinados a uso pessoal ou doméstico, como frascos de perfume, colheres, joias, estatuetas e bonecos articulados também eram inseridos nos loculi como spolia funerária (LUTRAAN, 2009, p. 5). ${ }^{7}$ A maior parte desses artefatos está hoje sob a guarda e curadoria do Museu do Vaticano, do Museu Britânico, do The Corning Museum of Glass de Nova lorque e do Museu Nacional de Belgrado.

${ }^{8}$ De acordo com Grig (2004, p. 206), 82\% das representações nos artefatos de vidro dourado fazem referência à temática religiosa. 


\section{A representação de Pedro e Paulo nos artefatos em vidro dourado}

No âmbito dos vidros dourados com temáticas cristãs, é digna de nota a grande quantidade de artefatos com as figuras de Pedro e Paulo, que, via de regra, eram representados em pares. Para nossa análise, selecionamos alguns desses exemplares, conforme vemos a seguir:

Figura 1 - Fragmento de artefato em vidro dourado com os bustos de Pedro e Paulo e, no centro, Cristo de corpo inteiro coroando os apóstolos (séc. IV)

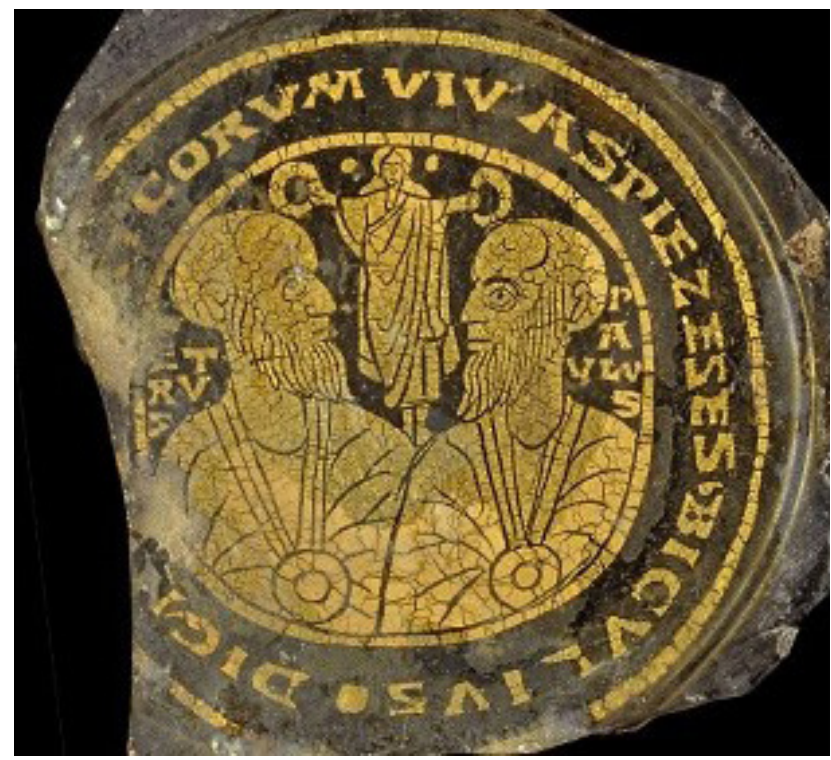

Local de depósito: Biblioteca Apostólica Vaticana. Fonte: MOREY, 1959.

Figura 2 - Fragmento de artefato em vidro dourado com Pedro e Paulo ao lado e Cristo,

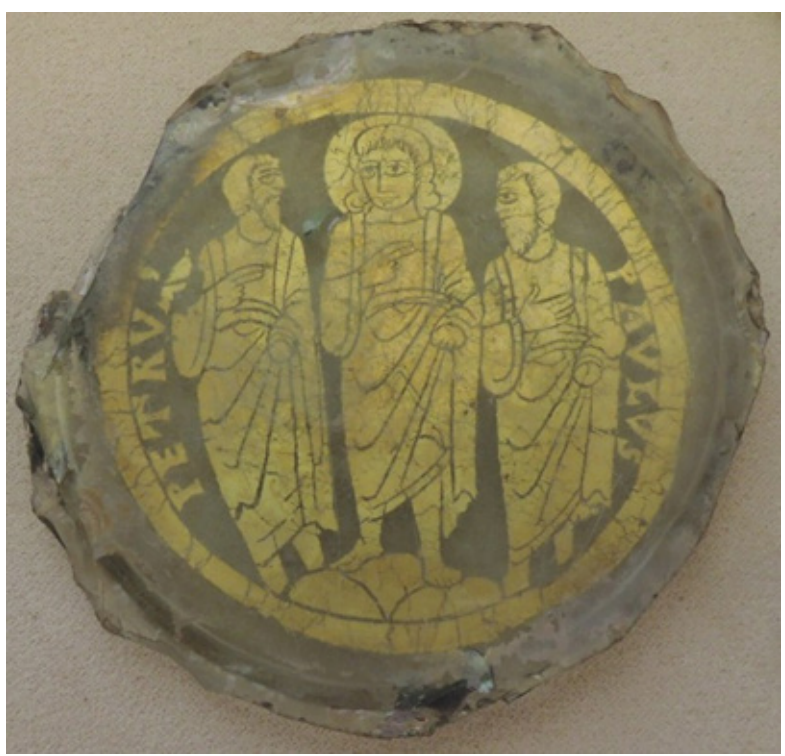

Local de depósito: Biblioteca Apostólica Vaticana. Fonte: MOREY, 1959. 
Figura 3 - Fragmento de artefato em vidro dourado com Pedro e Paulo sendo coroados (séc. IV)

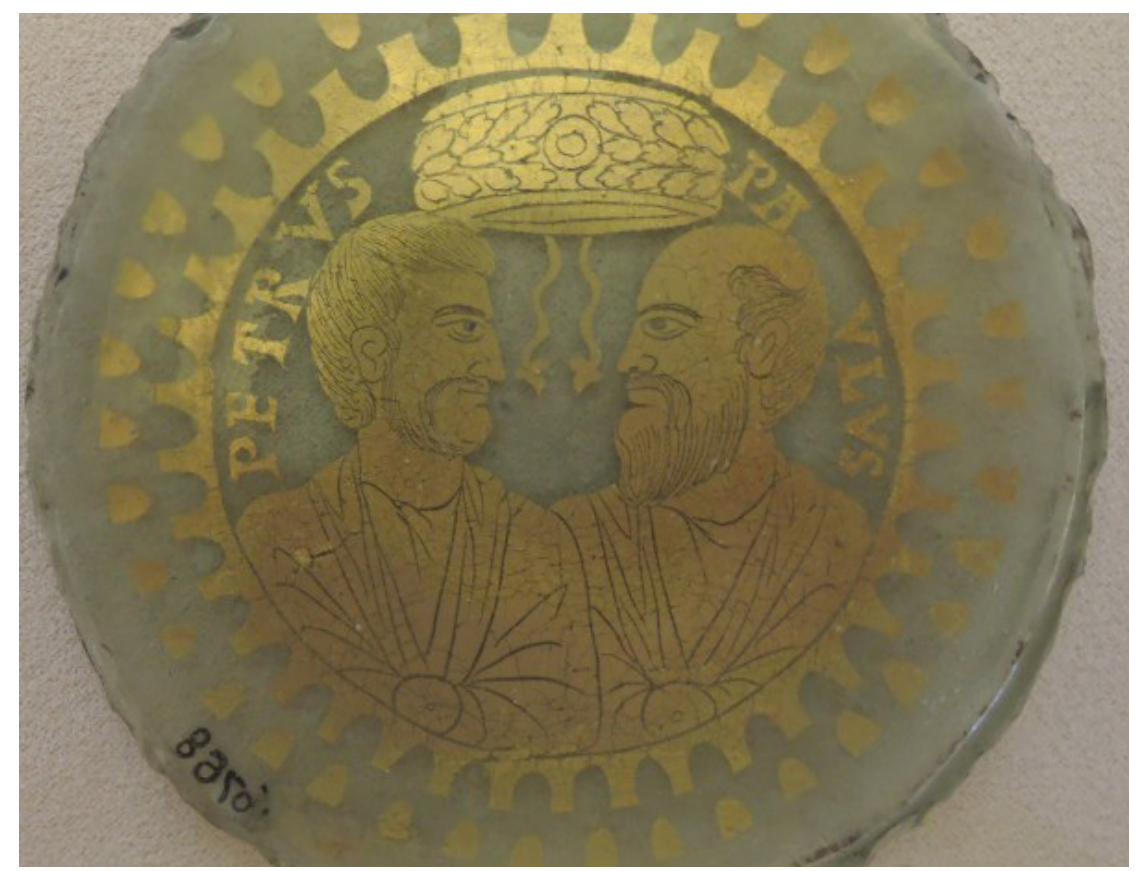

Local de depósito: Biblioteca Apostólica Vaticana. Fonte: MOREY, 1959.

Figura 4 - Fragmento de artefato em vidro dourado com Pedro e Paulo e um pequeno pergaminho ao centro (final do séc. IV)

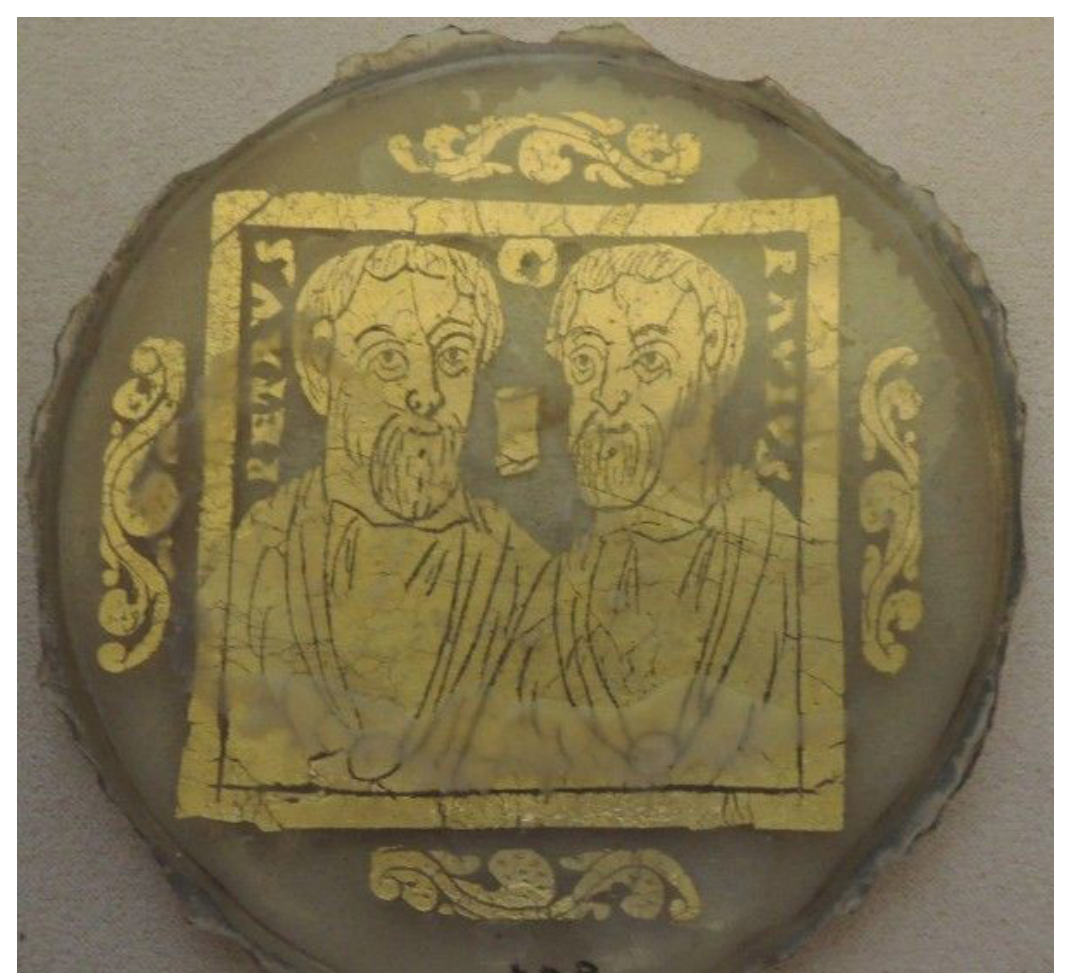

Local de depósito: Biblioteca Apostólica Vaticana. Fonte: MOREY, 1959. 
Figura 5 - Fragmento de artefato em vidro dourado com Pedro e Paulo com vários pergaminhos (séc. IV)

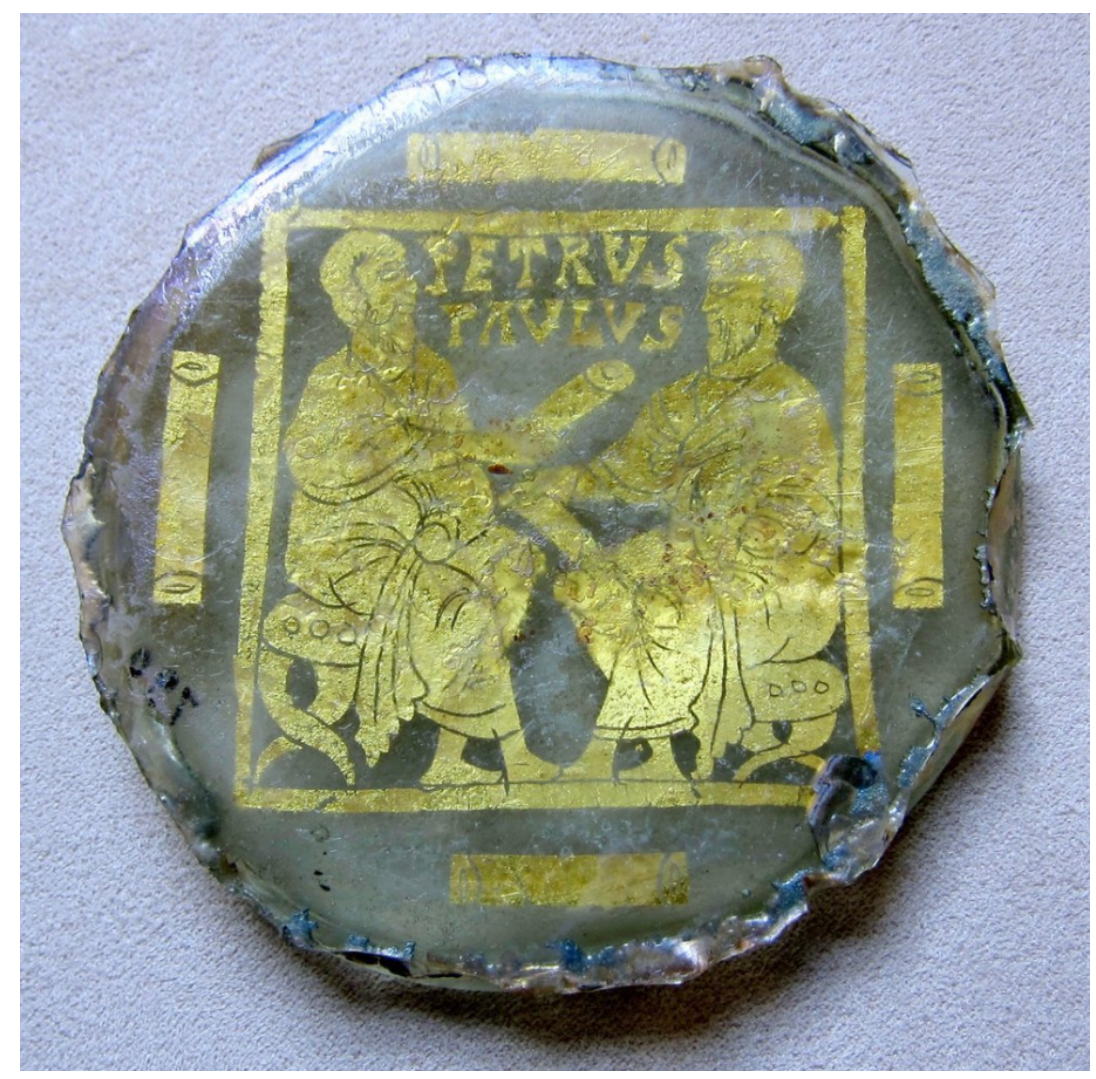

Local de depósito: Biblioteca Apostólica Vaticana. Fonte: MOREY, 1959.

Em quase todos os exemplares, Pedro e Paulo são identificados pelo título PETRVS (ET) PAVLVS, sendo Pedro, via de regra, situado à esquerda, sentado um pouco à frente de Paulo, situado à direita. Este posicionamento padrão estava vinculado à ideia de autoridade, o que também pode ser visto na iconografia imperial e nos retratos de casamento. O primero na linha de autoridade sempre era colocado à esquerda, no caso, Pedro; à direita, por sua vez, se colocava como o segundo na linha de autoridade, no caso, Paulo (HUSKINSON, 1982, p. 55).

Enquanto as peças em vidro dourado, geralmente, retratavam figuras humanas na posição frontal, Pedro e Paulo são, quase sempre, representados em meio perfil, talvez porque essa pose ajudasse a audiência a identificar as personagens. Vale destacar que a pose apostólica é uma imitação dos retratos de perfil de dupla face comumente empregados na cunhagem de moedas imperiais da Antiguidade Tardia, conforme vemos a seguir: 
Figura 6 - Moeda (frente e verso) em ouro sólido representando o imperador Teodósio I (379-395) encontrada em Tessalônica
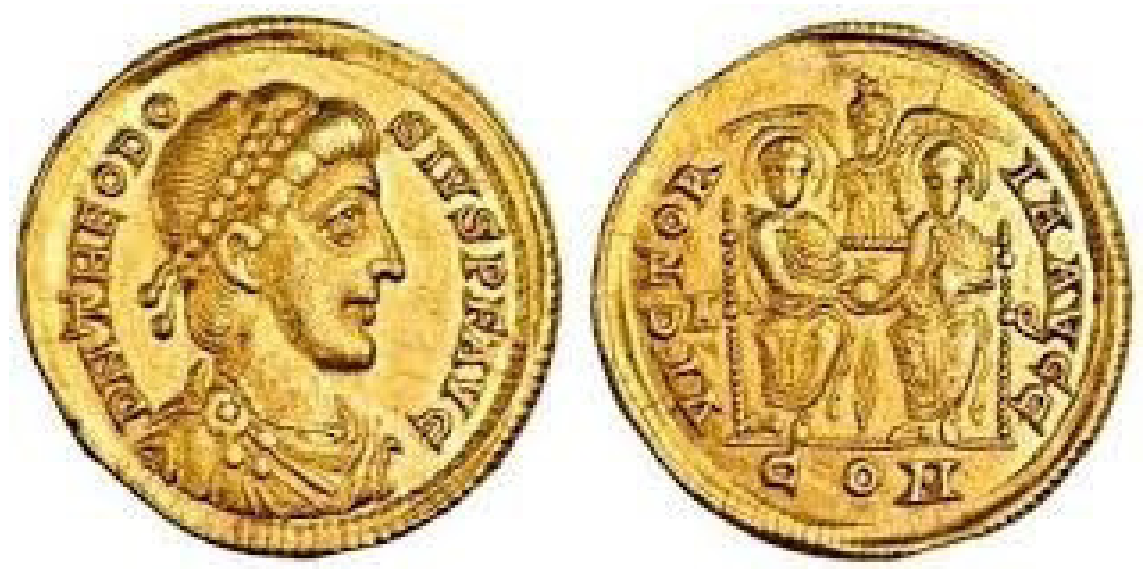

Fonte: Acervo particular da autora, 2020.

Acerca da indumentária utilizada pelas personagens, destacamos que se assemelha à dos filósofos e cidadãos romanos dos séculos IV e V. Ela consiste em uma túnica com mangas largas coberta com um pálio que atravessa a frente do corpo, dobrado entre os braços. Em algumas variantes, a túnica estava afixada com um broche circular no centro do peito (Fig. 1, 3 e 4). ${ }^{9}$

Alguns ícones da cultura pagã se fazem presentes nas representações, mas ganhando, obviamente, novos arranjos simbólicos. Nesse contexto, destacamos a utilização da coroa de louros (laurus nobilis) (Fig. 1, 3, e 4). A coroa de louros (uma trama composta por folhas de louro e ouro) era o modelo mais comum de "coroa de plantas" no Império Romano, mas não o único. Ela simbolizava o triunfo apoteótico, sendo oferecida pelos senadores aos combatentes vitoriosos no momento de entrada na cidade de Roma (Plínio, XV, III-V)..$^{10}$ Os imperadores romanos também eram coroados com louros, simbolizando seu poder terreno e celeste (ROGIĆ; GRAŠAR; NIKOLIĆ, 2012, p. 344). No cristianismo, a utilização da coroa de louros contrastava com a coroa de espinhos de

\footnotetext{
9 Enquanto os trajes apostólicos são razoavelmente padronizados, as fisionomias dos apóstolos variaram consideravelmente. É possível notar que a maioria das representações dos apóstolos datadas do século IV os apresentam com rostos claramente distintos: Pedro com uma cabeça cheia de cabelos cacheados e barba curta e Paulo calvo com a barba comprida, o que também pode ser visto no artefato acima. Todavia, nos artefatos do final do século IV e ao longo do século $V$, havia uma tendência a apresentar os dois apóstolos com características faciais quase idênticas, provavelmente devido, em parte, à produção em massa desses artefatos, o que acarretou menor precisão nos detalhes das peças.

${ }^{10} \mathrm{~A}$ origem do uso do adereço remonta à mitologia grega, mais especificamente à história de Dafne. Na história, Dafne se transformava em um loureiro para fugir de Apolo, que estava apaixonado por ela. Apesar da transformação em loureiro, Apolo resolve levar a ninfa consigo, fazendo-a seu símbolo desde então. Por esse motivo, na arte grega, Apolo era, costumeiramente, representado com uma coroa de louros. Em Atenas, muitos nobres também faziam uso da coroa de louros, por simbolizar distinção e glória, ainda que tenha sido substituída, algumas vezes, por ramos de oliveira (SMITH, 2014).
} 
Cristo (Jo 19:2; Mt 27:9), transmitindo a ideia do triunfo de Cristo sobre a morte e sua ressureição. Todavia, com a utilização do cristianismo como instrumento de poder após o governo de Constantino, a coroa de louros foi resignificada. Assim, a coroa usada sobre as cabeças de Pedro e Paulo simboliza o martírio desses - temática muito comum nas narrativas visuais e textuais do século IV -, a aproximação e lealdade recíprocas e deles para com Cristo, bem como o triunfo terreno e eterno da própria ekklesia.

Além da coroa de louros, Pedro e Paulo também são retratados com rolos de pergaminhos (Fig. 4 e 5), os quais representam claramente sua erudição e as Escrituras (LUTRAAN, 2009, p. 28). Todavia, essas cenas vão além ao transmitir a ideia de que os apóstolos foram os sucessores divinamente designados de Cristo e podiam falar com plena autoridade sobre todos os assuntos de interpretação das Escrituras, sendo, portanto, representantes naturais da ekklesia.

Acerca das inscrições, identificamos que, além dos títulos "PETRVS (ET) PAVLVS" presentes em todos os artefatos, há uma inscrição no arranjo circular da imagem da Figura 1, a saber: DIGNITAS AMICORVM VIVAS CVM TVIS ZESES ("Honra de amigos, que viva com seus parentes, que viva!"). Essa inscrição aparece em sete outros artefatos em vidro dourado com as mesmas representações imagéticas (Pedro, Paulo e Cristo). Observamos que a inclusão da fórmula ablativa CUM TVIS faz referência, explicitamente, ao fato de que as pessoas representadas tinham vínculos familiares e/ou relações pessoais bastante próximas. Isso pode ser comprovado pelos diversos objetos em vidro dourado com retratos de família que apresentam esta mesma fórmula. Logo, a expressão usada serve para enfatizar, sob uma ótica comemorativa e celebrativa, o forte vínculo pessoal estabelecido entre Pedro, Paulo e Cristo.

A partir da análise dos símbolos e inscrições presentes nos artefatos em questão, entendemos que as figuras de Pedro e Paulo eram a personificação dos ideais romanos de amicitia e concordia. Sobre esse assunto, o que caracterizava as relações de amicitia era o fato de as pessoas se reconheciam como membros de um mesmo grupo, o que garantia a eles as mesmas honras e status, sendo que a inscrição da Fig. 1 deixa isso claro. Vale destacar que, na obra De Amicitia $(14,51)$, Cícero aponta que há dois tipos de amizades distintas: uma verdadeira, pautada na virtude, e uma falsa, pautada nas benesses e prazeres, perdurando enquando os bens do amicus explorado ainda existem. Abarcando virtudes como compromisso, unidade, harmonia e concordância, o ideal de concordia, por sua vez, de acordo com Russell (2013, p. 213), surge no período republicano e referese, essencialmente, a uma relação horizontal entre iguais, particularmente no âmbito das elites governamentais. No contexto político romano, a concordia entre magistrados, censores e cônsules era tida como um importante mecanismo de controle para as ações 
do governo. Somente no final da República, após o consulado de Cícero (63 a.C.) e, em particular, durante a Terceira Guerra Civil Romana (43-42 a.C.), a ideia de concordia foi ampliada e passou a incluir todos os cidadãos. Nesse contexto, os rolos de pergaminho e a coroa de louros presentes na iconografia seriam representações do ideal de concordia apostolorum, enfatizando a harmonia e a lealdade entre os apóstolos.

Embora Pedro e Paulo sejam frequentemente descritos como parceiros únicos ou mesmo companheiros de Cristo, eles também eram retratados ao lado de um ou mais santos, bispos ou mártires. No caso de santos, mártires e figuras veneráveis que aparecem nas peças em vidro dourado, é possível pontuar, a partir dos registros epigráficos, os seguintes: Agnes, Casto, Dion, Eleito, Félix, Floco, Genésio, Joane, Judas, Júlio, Justo, Laurentino, Lucas, Maria, Pastor, Peregrina, Filipe, Proto, Silvano, Simão, Estéfano, Timóteo, Tomé, Urso e Vicente. Essas figuras são, via de regra, representadas como companheiros de retrato ou em grupos de três ou mais, conforme vemos abaixo (Figuras 7 e 8).

Figura 7 - Fragmento de artefato em vidro dourado com a figura de Maria orante ao centro e Pedro e Paulo nas laterais (séc. IV)

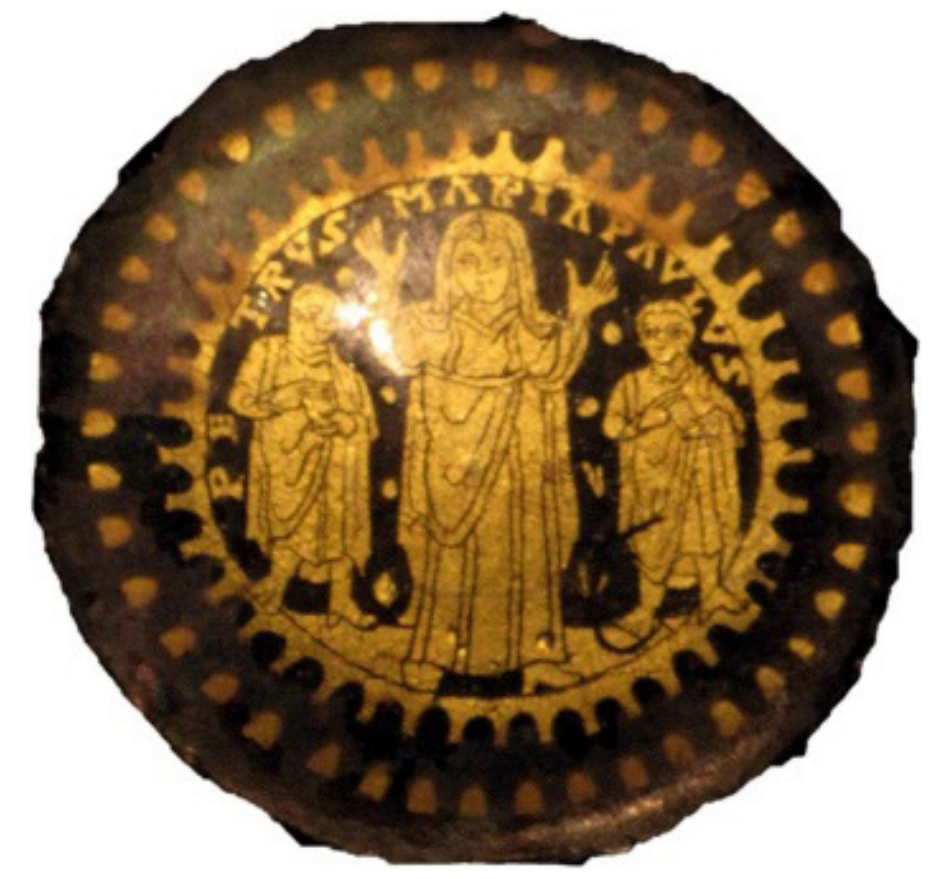

Local de depósito: Biblioteca Apostólica Vaticana. Fonte: MOREY, 1959.

A utilização das figuras dos santos e mártires associada às imagens de Pedro e Paulo era uma forma de propaganda da fé, na medida em que oferecia uma chancela eclesiástica à devoção a essas personagens. 
Figura 8 - Fragmento de artefato em vidro dourado com a figura de Santa Agnes orante ao centro e os bustos de Pedro e Paulo nas laterais (séc. IV)

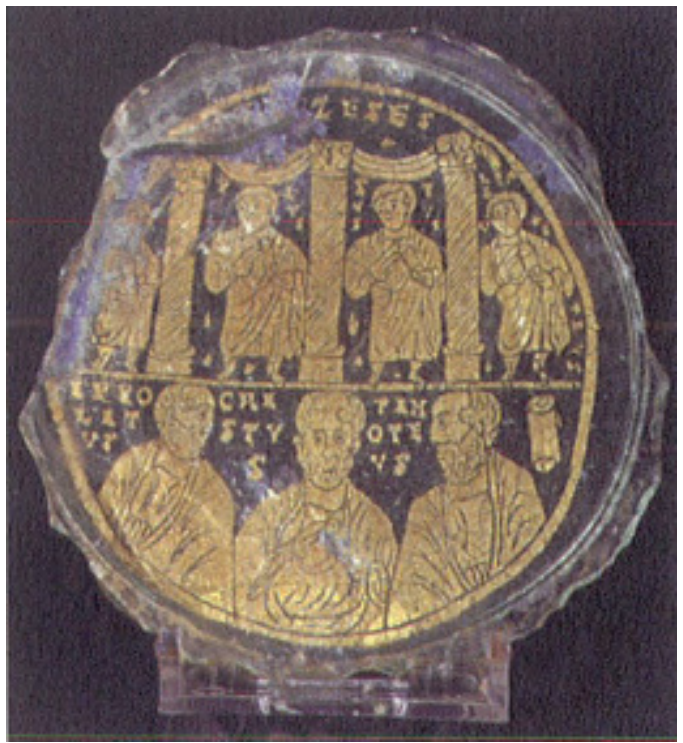

Local de depósito: Biblioteca Apostólica Vaticana. Fonte: MOREY, 1959

Já no caso da utilização da figura dos bispos que também aparecem representados nos artefatos associados a Pedro e Paulo, a ideia era fazer uma propaganda destes como herdeiros diretos da autoridade dos apóstolos Pedro e Paulo. Vale destacar que os bispos retratados foram Sixto, Cipriano (ambos também mártires), Marcelino, Hipólito, Calisto e Dâmaso.

Figura 9 - Fragmento de artefato em vidro dourado com os bustos de Pedro, Paulo, Dâmaso e Jesus

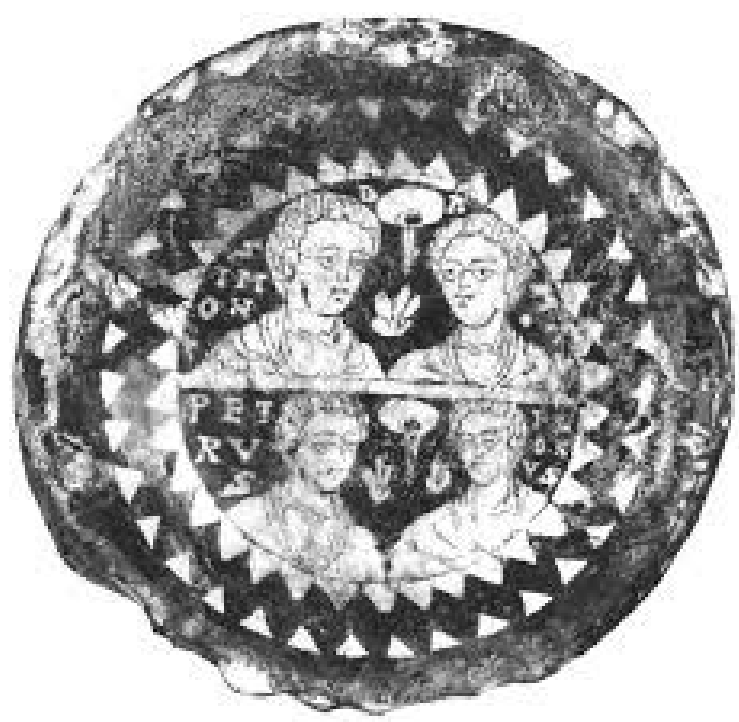

Local de depósito: Biblioteca Apostólica Vaticana. Fonte: MOREY, 1959. 
Uma das principais questões que se colocam quando analisamos os objetos em vidro dourado está pautada na intencionalidade das iconografias e epigrafias. Parte da historiografia já pontuou que muitos deles foram feitos com o intuito de retratar seus proprietários por meio de reproduções de suas imagens, enquanto que alguns outros foram forjados para celebrar algum evento (LUTRAAN, 2009; GRIG, 2004; WHITEHOUSE, 1996). No caso dos artefatos cristãos, dada a repetição e a constância com que as imagens de Pedro e Paulo aparecem, entendemos que a maior parte deles seria usada em eventos comemorativos. ${ }^{11}$ Isso pode ser provado ainda quando analisamos o Cronógrafo de 354, também conhecida como Calendário de 354 ou Calendário de Filócalo. ${ }^{12} \mathrm{O}$ programa temático do Cronógrafo de 354 dialoga consideravelmente com as representações nos artefatos em vidro dourado, conforme vemos abaixo:

\author{
DEPOSITIO EPISCOPORUM \\ VI kal. Ianuarias Dionisi, in Callisti. \\ III kal. lanuar. Felicis, in Callisti. \\ prid. kal. lanuar. Silvestri, in Priscillae. \\ III idus lanuarias Miltiadis, in Callisti. \\ XVIII kal. Feb. Marcellini, in Priscillae. \\ III non. Mar. Luci, in Callisti. \\ $X$ kal. Mai. Gai, in Callisti. \\ IIII non. Augustas Stephani, in Callisti. \\ VI kal. Octob. Eusebii, in Callisti. \\ VI idus Decemb. Eutychiani, in Callisti. \\ non. Octob. Marci, in Balbinae. \\ prid. idus Apr. Iuli, in via Aurelia miliario III, in Callisti. \\ (Cronógrafo de 354, ITEM DEPOSITIO EPISCOPORUM).
}

ITEM DEPOSITIO MARTIRUM

VIIIkal.Jan.Natus Christus in Bethleem Judeae.

XIIlkal.Feb.Fabiani in Callisti, et Sebastiani in Catacumbas.

Xllkal.Feb.Agnetis in Nomentana.

VIIIkal.Mart.Natale Petri de Cathedra.

Nonis Martii Perpetuae et Felicitatis Africae.

XIVkal.Jun.Parthini et Caloceri in Callisti Diocletiano IX. et Maximiano VIII. Coss.

\footnotetext{
${ }^{11}$ Katherine Lutraan (2009) pontua que a maior parte dos artefatos em vidro dourado contém um modelo epigráfico bastante repetitivo, com fórmulas um tanto ou quanto genéricas. $\mathrm{O}$ esquema padrão sugere que os artefatos eram produzidos em massa e tinham muita popularidade.

${ }^{12} \mathrm{O}$ senador romano cristão Valentino foi o resposável pela criação de um códice contendo um calendário ilustrado, denominado Cronógrafo de 354, o qual, possivelmente, foi elaborado ao longo do ano 353 . Além do calendário, o documento apresenta listas com nomes de cônsules, prefeitos e bispos da cidade de Roma até aquela data, além de ilustrações que incluíam representações dos cônsules daquele ano e símbolos astrológicos. A caligrafia é de excepcional qualidade, sendo obra do mais famoso calígrafo do século IV, Fúrio Dionísio Filócalo. As ilustrações que acompanharam o texto foram as primeiras feitas em página inteira em um códice na História da Arte Ocidental. O códice original continuou a ser útil muito depois da época de Valentino. Polêmio Sílvio, no ano 449, provavelmente consultou o códice para confecionar o seu próprio calendário. No século VI, foi preparado um planisfério para o ano 579 que parece ter sido feito com cópias das ilustrações do códice de 354. Ao menos 20 códices do século IV sobrevivem completamente. No Renascimento, a descoberta de uma cópia do manuscrito feita no século IX causou grande euforia, inspirando várias cópias durante os séculos XVI e XVII. Nosso conhecimento do texto é, portanto, mediado pelas cópias renascentistas sobreviventes, mas nenhuma delas é adequada por si só (BURGESS, 2013).
} 
Illkal.Jul.Petri in Catacumbas et Pauli Ostense, Tusco et Basso Coss.

Vlid. Felicis et Filippi in Priscillae: et in Jordanorum, Martialis Vitalis, Alexandri: et in Maximi, Silani (hunc Silanum martirem Novati furati sunt) et in Praetextati, Januarii.

Illkal. Aug. Abdos et Senen in Pontiani, quod est ad Ursum pileatum.

VIIlid. Aug. Xysti in Callisti, et Praetextati, Agapiti et Felicissimi.

VIlid. Aug. Secundi, Carpofori, Victorini et Severiani Albano et Ostense.

VI Ballistaria Cyriaci, Largi, Crescentiani, Memmiae Julianetis et Smaragdi.

IV id. Laurentii in Tiburtina.

Idib.Aug. Hippolyti in Tiburtina et Pontiani in Callisti.

XI kal. Sept. Timotei Ostense.

$\checkmark$ kal. Hermetis in Basillae, Salaria vetere.

Nonis Sept.Aconti in Porto, et Nonni et Herculani et Taurini.

$V$ id. Gorgoni in Labicana.

III id. Prothi et Hyacinthi in Basillae

XVIII kal. Oct. Cypriani Africae, Romae celebratur in Callisti.

$X$ kal. Oct. Basillae Salaria vetere Diocletiano IX et Maximiano VIII. Coss.

Pridie Idus Octob. Callisti in via Aurelia, miliario III.

$\mathrm{V}$ id.Novemb. Clementis, Semproniani, Claudi, Nicostrati in Comitatum.

III kal. Dec.Saturnini in Trasonis.

Idibus Decemb. Ariston in Pontum.

(Cronógrafo de 354, ITEM DEPOSITIO MARTIRUM).

O Cronógrafo de 354 evidencia, dentre outras coisas, que os cristãos do século IV, assim como os pagãos com suas deidades, promoviam habitualmente comemorações aos seus ícones: Jesus, Maria, os apóstolos, os mártires, os bispos e figuras veneráveis. De fato, entre 350 e 410, Roma sediou alguns dos mais importantes eventos cristãos anuais, que recebiam devotos que peregrinavam para a cidade advindos de várias partes do Império. Curiosamente, a maior parte das personagens retratadas nos artefatos estão também presentes no Cronógrafo de 354, o que nos faz supor que a cultura material era parte integrante de um programa comemorativo cristão em honra às personagens sagradas nesses eventos.

É imporante destacar que a alta padronização dos artefatos em vidro dourado indica que estes foram produzidos em massa e em grande escala, possivelmente para um evento que exigisse uma grande demanda dos objetos. Logo, essas celebrações, em algum momento, podem ter fomentado a produção de artefatos dessa natureza, os quais eram adquiridos ou distribuídos a título de lembrança e propaganda para aqueles que faziam peregrinações a Roma para participar desses festejos.

Dado o caráter formular e genérico das temáticas dos objetos, bem como o fato de terem sido fabricados em massa, estes revelam que devem ter sido patrocinados por uma aristocracia cristã, assim como o próprio Cronógrafo de 354 também foi. Essa aristocracia cristã, assim, exigia que os artesãos obedecessem a certas disposições estéticas específicas que facilitassem a comunicação com a audiência. 
Seguindo as caracteríticas básicas da propaganda - simplificação, saturação, parcialidade, deformação e falta de inovação -, os artefatos em vidro dourado analisados se colocam como narrativas visuais endereçadas a uma audiência plural, na forma de esforço educacional visando a um fim específicio.

\section{Considerações finais}

A arte cristã dos séculos IV e V definitivamente não inventou qualquer padrão estético. Ao contrário, ela é claramente derivada das convenções da arte clássica. Falamos de traçados, cores, formas, materiais e suportes que em nada diferem da arte pagã ou judaica, até porque as oficinas recebiam encomendas de todos os vieses religiosos. Se, por um lado, as convenções da arte clássica foram utilizadas amplamente para a arte cristã, por outro lado, as narrativas visuais das obras se assemelhavam àquelas empregadas na arte imperial romana de cunho comemorativo. Logo, a arte cristã tardia apresentou um forte apelo aos temas vinculados à autoridade apostólica ao invés de focar, por exemplo, na biografia apostólica. Além de as representações de histórias canônicas serem pouco frequentes, aquelas que sobreviveram sugerem um forte viés a favor de Pedro e Paulo, em detrimento dos outros apóstolos.

A iconografia e a epigrafia presentes nos artefatos cristãos em vidro dourado evidenciam as alterações político-religiosas que caracterizaram a ekklesia cristã no Império tardio. No caso específico dos objetos com as figuras de Paulo e Pedro - tanto sozinha quanto associada aos bispos, santos e mártires -, dada a ubiquidade com que são apresentadas, nos levam a supor que tais objetos faziam parte de um programa propagandístico comemorativo financiado por famílias cristãs da aristocracia ou pelos bispos de Roma com o intuito de promover a autoridade episcopal e eclesiástica diante da forte concorrência com as heresias e o paganismo. Entendemos que a visibilidade dos apóstolos Pedro e Paulo - pautada nos ideais de amicitia e concordia - bem como dos bispos, mártires e santos nos artefatos em vidro dourado não ocorreu por acaso, mas serviu para garantir a audiência daqueles que utilizavam tais objetos. Por meio desses artefatos, a ekklesia era exaltada como instituição com integridade apostólica, verdadeira herdeira daqueles que foram baluartes do cristianismo, Pedro e Paulo. No caso específico dos ideais de concordia e a amicitia, heranças da cultura romana, estes constituíam virtudes fundamentais para a manutenção da unidade, reconhecimento e harmonia religiosa, política e social na ekklesia romana na época tardia.

Desse modo, aplicando critérios estéticos e temáticos semelhantes àqueles utilizados para as obras de arte dedicadas ao poder político na Antiguidade Tardia, os 
artefatos em vidro dourado cristãos faziam parte de um repertório propagandístico de apoteose do poder político-religioso da ekklesia que, ainda nos séculos IV e V, estava em vias de institucionalização.

\section{Referências}

\section{Documentação textual}

BÍBLIA DE JERUSALÉM revista e ampliada. Tradução da École Biblique de Jerusalem. São Paulo: Paulus, 2006.

CÍCERO. Sobre a amizade. Tradução de João Teodoro d'Olim Marote. São Paulo: Nova Alexandria, 2006.

PLINIO. Natural History. Libri XII-XVI. Translated by H. Rackham. Cambridge: Harvard University Press, 1968.

\section{Documentação visual}

FURIUS DIONYSIUS FILOCALUS. Kalendarium Anno CCCLIV Conscriptum. Documenta Catholica Omnia. Disponível em: https://www.documentacatholicaomnia. eu/30_10_03540354_Furius_Dionysius_Filocalus.html. Acesso em: 04 dez. 2020.

MOREY, C. R. The gold-glass collection of the Vatican Library: with additional catalogues of other gold-glass collections. Roma: Biblioteca Apostolica Vaticana, 1959.

\section{Obras de apoio}

BARAG, D. Alexandrian and Judaean glass in the price Edict of Diocletian. Journal of Glass Studies, v. 47, p. 184-186, 2005.

BOBBIO, N.; MATEUCCI, N.; PASQUINO, G. (org.). Dicionário de política. Brasília: Editora da UnB, 1983.

BURGESS, R. W. The Chronograph of 354: its manuscripts, contents, and history. Journal of Late Antiquity, n. 5.2, p. 345-396, 2013.

EVANS, J. D. The art of persuasion: political propaganda from Brutus to Aeneas. Ann Arbor: University of Michigan Press, 1992.

GRIG, L. Portraits, pontiffs and the Christianization of fourth-century Rome. Papers of the British School at Rome, v. 72, p. 203-230, 2004. 
HOWELLS, D. T. Late Antique gold glass in the British Museum. 2010. Thesis (Doctor of Philosophy in Art History) - University of Sussex, Sussex, 2010.

HUSKINSON, J. M. Concordia Apostolorum: Christian propaganda at Rome in the fourth and fifth centuries. Oxford: BAR, 1982.

LOWE, E. A. Codices latini antiquiores: a palaeographical guide to Latin manuscripts prior to the ninth century. Part 1: The Vatican City. Oxford: Oxford Clarendon Press, 1934.

LUTRAAN, K. Late Roman gold-glass: images and inscriptions. 2009. Dissertation (Master of Arts) - School of Graduate Studies, McMaster University, Hamilton, 2009.

RANCIÈRE, J. O dissenso. In: NOVAES, A. (org.). A crise da razão. São Paulo: Companhia das Letras, 1996, p. 367-382.

ROGIĆ, D.; GRAŠAR, J. A.; NIKOLIĆ, E. Wreath - its use and meaning in ancient visual culture. Religion and tolerance. Journal of the Center for Empirical Researches on Religion, v. X, n. 18, p. 341-358, 2012.

RUSSELL, A. Concordia: word, concept, goddess? The Classical Review, n. 65, p 212-214, 2013.

SAGE, E. T. Advertising among the Romans. The Classical Weekly, v. 9, n. 26, p. 202-208, 1916.

SMITH, S. D. Man and animal in Severan Rome: the literary imagination of Claudius Aelianus. Cambridge: Cambridge University Press, 2014.

SYME, R. Livy and Augustus. Harvard Studies in Classical Philology, n. 64, p. 27-87, p. 2787, 1959.

WALSH, P. G. Livy and the aims of 'historia'. An analysis of the third decade. Nova York: Walter de Gruyter, 1982.

WHITEHOUSE, D. Glass, gold, and gold-glasses. Expedition, v. 38. n. 2, p. 5-12, 1996. 